\title{
Microvesicles and exosomes: new players in metabolic and cardiovascular disease
}

\author{
Charlotte Lawson', Jose M Vicencio ${ }^{2}$, Derek M Yellon ${ }^{2}$ and Sean M Davidson ${ }^{2}$ \\ 'Department of Comparative Biomedical Sciences, Royal Veterinary College, Royal College Street, \\ London NW1 0TU, UK \\ ${ }^{2}$ The Hatter Cardiovascular Institute, University College London, London WC1E 6HX, UK
}

Correspondence should be addresses to C Lawson

Email

chlawson@rvc.ac.uk

\begin{abstract}
The past decade has witnessed an exponential increase in the number of publications referring to extracellular vesicles (EVs). For many years considered to be extracellular debris, EVs are now seen as novel mediators of endocrine signalling via cell-to-cell communication. With the capability of transferring proteins and nucleic acids from one cell to another, they have become an attractive focus of research for different pathological settings and are now regarded as both mediators and biomarkers of disease including cardio-metabolic disease. They also offer therapeutic potential as signalling agents capable of targeting tissues or cells with specific peptides or miRNAs. In this review, we focus on the role that microvesicles (MVs) and exosomes, the two most studied classes of EV, have in diabetes, cardiovascular disease, endothelial dysfunction, coagulopathies, and polycystic ovary syndrome. We also provide an overview of current developments in MV/exosome isolation techniques from plasma and other fluids, comparing different available commercial and non-commercial methods. We describe different techniques for their optical/biochemical characterization and quantitation. We also review the signalling pathways that exosomes and MVs activate in target cells and provide some insight into their use as biomarkers or potential therapeutic agents. In summary, we give an updated focus on the role that these exciting novel nanoparticles offer for the endocrine community.
\end{abstract}
Keywords
- diabetes
- heart
- endothelium
- microvesicles
- nanoparticles
- exosomes
- microRNA

\section{Introduction}

It is well established that patients with metabolic diseases, in particular insulin resistance and type 2 diabetes mellitus (T2DM), are more than twice as likely to develop accelerated cardiovascular disease (CVD) including atherosclerosis, stroke, and coronary artery disease (reviewed in Rask-Madsen \& King (2013)). Coronary artery disease is a major cause of morbidity and mortality worldwide, and is a leading cause of death in T2DM, with excess risk of fatality in women compared with men (Peters et al. 2014). Extensive coronary artery disease can result in myocardial infarction, severe loss of cardiac function, and subsequently lead to the development of heart failure (Hausenloy \& Yellon 2013). A cluster of risk factors have recently been defined by the American Diabetes Association and the American College of Cardiology Foundation as reliable indicators of a patient's risk for T2DM and CVD, and has been defined as cardiometabolic risk (CMR; Brunzell et al. 2008). These risks include obesity, hyperglycemia, hypertension, insulin resistance, and dyslipidemia. The presence of secondary CVD in patients

Published by Bioscientifica Ltd. 
with ischaemia-reperfusion (IR) or T2DM may be referred to as cardio-metabolic disease (CMD). Given its increasing prevalence and severe consequences, new approaches are needed to diagnose and treat CMD.

Extracellular vesicles (EVs) are small (50 nm to $2 \mu \mathrm{m})$ vesicles released from the surface of many different cell types into different bodily fluids, including plasma, milk, saliva, sweat, tears, semen, and urine. There are several classes of EV, including exosomes, microvesicles (MVs), and apoptotic bodies, which are produced by different mechanisms. Attracting perhaps the most attention recently have been exosomes (50-100 nm), a homogenous population of $\mathrm{EV}$ which are released from cells when multivesicular bodies (MVB; sometimes called multivesicular endosomes, MVE) fuse with the plasma membrane in a highly regulated process and release their contents. Cells can also produce a more heterogeneous population of EVs up to $2 \mu \mathrm{m}$ in diameter called MVs, which are formed by budding and shedding of the cell membrane, a process that involves calcium dependent signalling and enzyme activity. Cells undergoing apoptosis also typically release $\mathrm{EV}$ of $1-5 \mu \mathrm{m}$ in diameter which are referred to as apoptotic bodies (Dignat-George \& Boulanger 2011, van der Pol et al. 2012, Colombo et al. 2014) (Fig. 1).

In some literature, MVs isolated by centrifugation are referred to as 'microparticles,' particularly those isolated from platelets or endothelial cells. For clarity, this review will refer to EVs simply as exosomes or MV on the basis of the mechanism of their cellular production and their size range - an approach that has been taken by others (Thery et al. 2009), with the caveat that most isolation methods do not provide a pure populations of vesicles. It is important to note that the size ranges of EVs may overlap and in particular, the size of MVs could overlap with the exosomal size range. Where a mixture of exosomes and MV is likely, for example when plasma vesicles are isolated by high speed $(\sim 100000 \boldsymbol{g})$ ultracentrifugation, we refer to them more broadly as EV. These EV are sometimes also referred to as 'exosome-like vesicles'.

One of the characteristic markers of all EVs is the presence on the outer surface of phosphatidyl serine (PS), due to loss of membrane asymmetry during blebbing (apoptotic bodies) or budding (MV) and inward folding of the membrane during vesicle formation in MVBs (exosomes). This can be identified by binding of labelled annexin $\mathrm{V}$, a reagent often used for flow cytometric analysis of apoptotic cells. However, more recently several groups have identified MVs lacking PS on the outer membrane, suggesting that this is not essential for MV formation (Larson et al. 2012, Hou et al. 2014).
Both exosomes and MVs characteristically carry a cargo, which they are able to deliver to cells in remote locations. The cargo can include genetic material such as mRNA, microRNA (miRNA), or even small amounts of DNA (Moldovan et al. 2013), and proteins including transcription factors, cytokines, and growth factors, have also been described. Importantly, MVs also carry cellular receptors and transmembrane proteins on their surface characteristic of the cells from which they were released. This aids in their identification but also means that they can interact with specific target cells instigating signalling cascades via receptor interactions (rececrine signalling akin to cell-cell interactions) and also increasing specificity of cargo delivery. On the other hand, exosomes are characteristically decorated with markers including Alix, HSP70, and the tetraspanins CD9 and CD63, which may be associated with beta- 2 integrin binding and intercellular communication. Although these are commonly used as markers of exosomes, they are not exclusive to exosomes and may be found on other EVs. Furthermore, not all EVs express CD63 and different sub-populations of exosomes may express different markers (Thery et al. 2009). It is important to consider that exosomes do not necessarily express the same marker proteins as their parent cells. For example, we found that the common endothelial marker CD144 is absent on exosomes from human umbilical vein endothelial cells (HUVECs) (Fig. 2). Recent work has further defined plasma EV and exosome surface marker expression by using extensive antibody profiling which showed that exosomes can express surface membrane markers such as CD146, CD4, CD3, and CD45 (Jorgensen et al. 2015). There is some evidence that the protein and RNA content of exosomes depends on the state of the source cell (de Jong et al. 2012).

The mechanism behind the formation of exosomes and selective packaging of proteins, lipids, and RNA is not completely understood but is gradually becoming revealed. The Endosomal Sorting Complex Responsible for Transport pathway does not seem to be required for exosome biogenesis, although some components are involved in their formation, particularly Alix (Trajkovic et al. 2008, Baietti et al. 2012, Raposo \& Stoorvogel 2013). Other molecules that are enriched in exosomes such as tetraspanins and ceramide have also been implicated in exosome biogenesis. For example, inhibitors of neutral sphingomyelinase, an enzyme involved in ceramide production, inhibits exosome production (Trajkovic et al. 2008). Less well understood is the mechanism of exosome release. Certain members of the Rab GTPase family are required for efficient release of exosomes, although the

Published by Bioscientifica Ltd. 


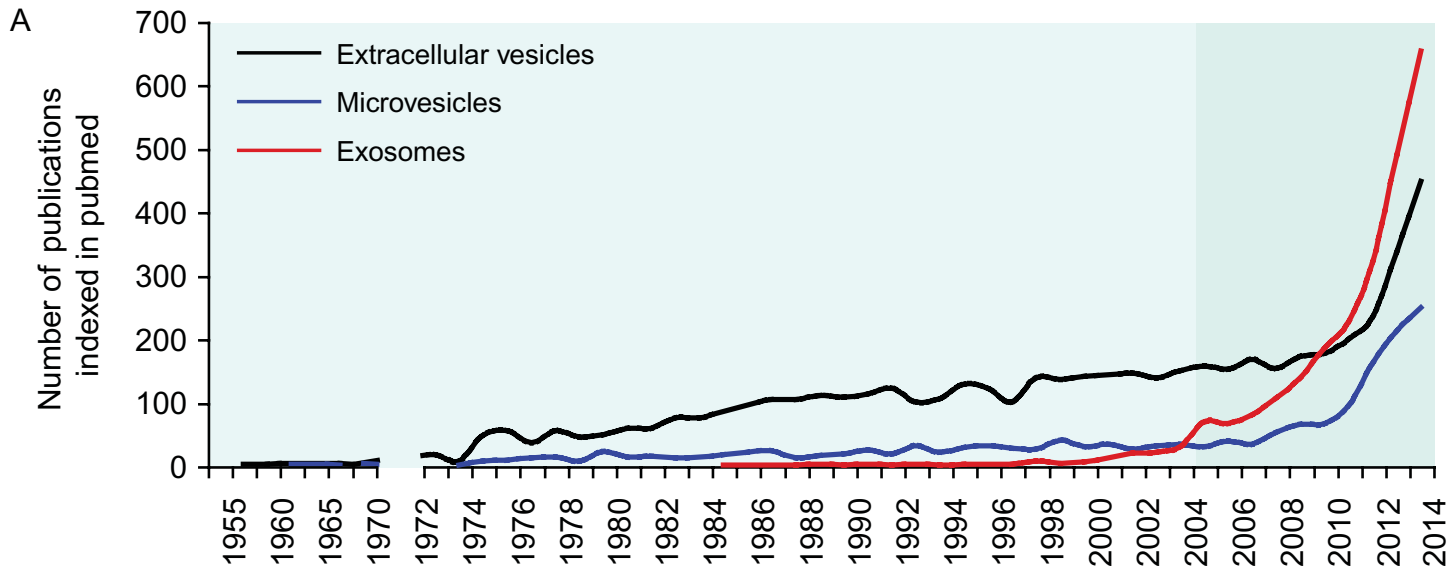

$\mathrm{B}$

Year

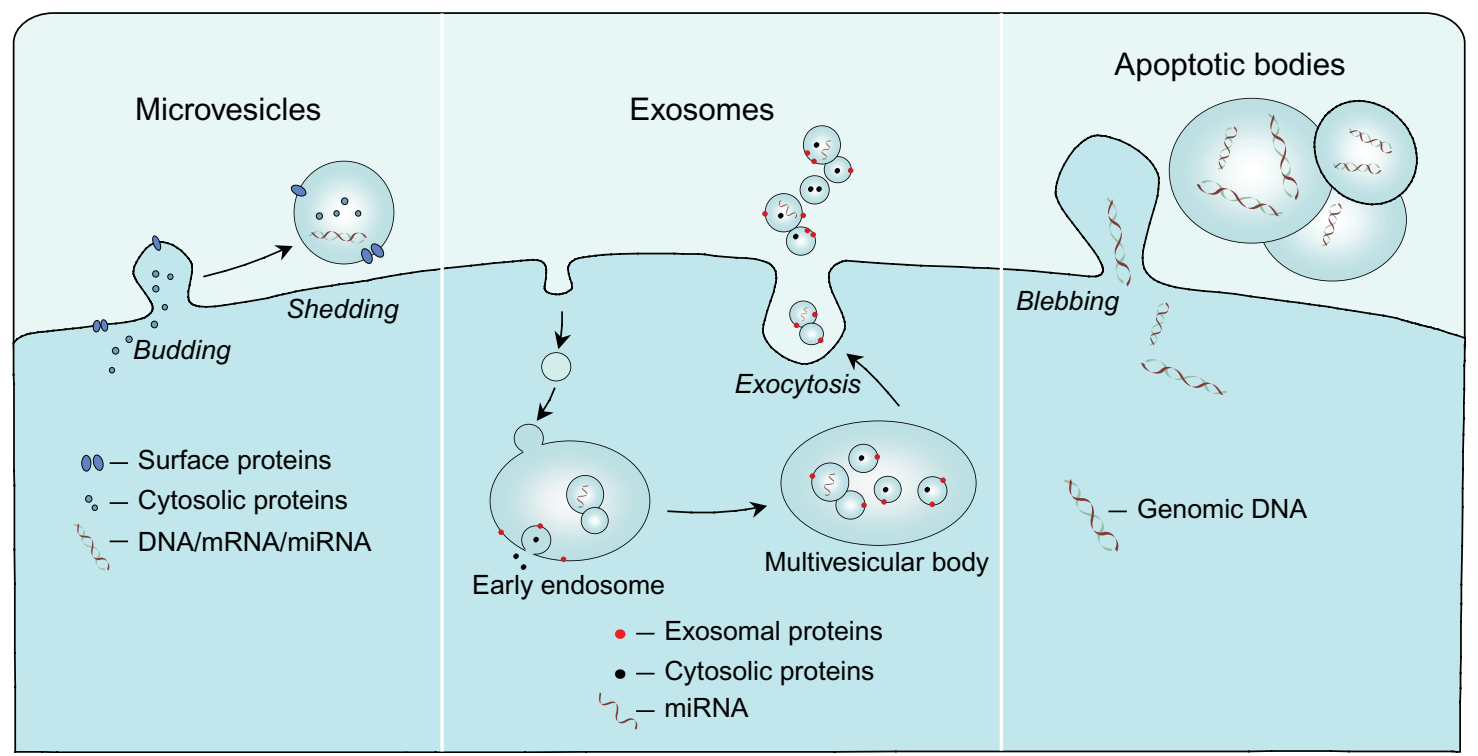

\section{Figure 1}

(A) Timeline (1956-2014) of the publications referring to extracellular vesicles (black line), microvesicles (blue line), and exosomes (red line). (B) Schematic representation of the mechanisms of formation of microvesicles, exosomes, and apoptotic bodies. Microvesicles $(0.2-2.0 \mu \mathrm{m})$ originate via budding and shedding from the plasma membrane of cells and therefore may contain specific surface markers from the cell of origin.

exact members involved appears to depend on the cell type and experimental design, and may reflect different subtypes of exosomes relating to the stage (early or late) of endosome/MVB formation (Colombo et al. 2014).

\section{Purification of EVs from different bodily fluids}

Although MVs and exosomes are produced by distinct mechanisms, their sizes overlap, and most isolation protocols do not isolate a pure population. Therefore, in order to evaluate published experiments it is important to
Exosomes (50-100 $\mathrm{nm}$ ) on the other hand originate intracellularly through a sorting pathway involving intermediate organelles such as the early endosome and a late multivesicular body, which fuses with the plasma membrane to release exosomes via exocytosis. Apoptotic bodies (1-2 $\mu \mathrm{m})$ originate via blebbing of the plasma membrane.

understand what type of $\mathrm{EV}$ is most likely to be isolated by different protocols.

A number of different protocols have been optimized for purification of different classes of EVs from different sources, with isolation from plasma being the best described (reviewed in Witwer et al. (2013) and Lobb et al. (2015). The isolation of EVs from blood requires its rapid collection with an anti-coagulant - citrate is now generally advised (Lacroix et al. 2012). The most straightforward technique for isolation of EVs involves sequential steps of centrifugation. After the collection of plasma by

Published by Bioscientifica Ltd 

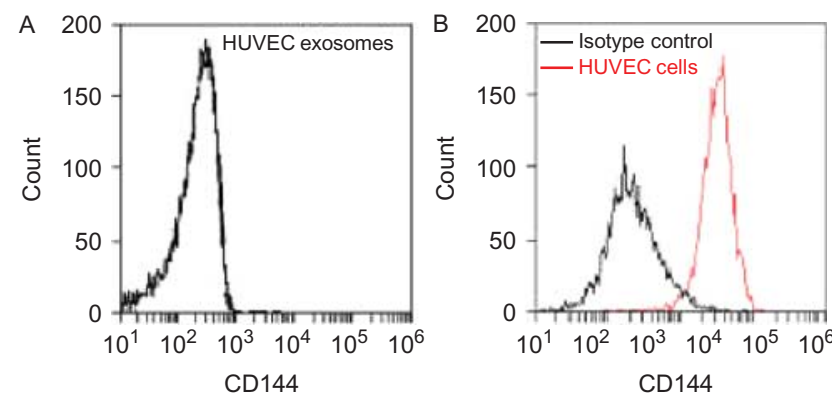

Figure 2

The endothelial cells marker CD144 is absent from exosomes isolated from HUVEC endothelial cells (A), despite being detectable on the parent cells (B). HUVEC cells or HUVEC exosomes bound to $4 \mu \mathrm{m}$ beads were labelled with anti-CD144 and fluorescent secondary antibody, before fluorescent detection using a BD AccuriC6 flow cytometer.

centrifugation at $1500 \times \boldsymbol{g}$ for $15 \mathrm{~min}$, the supernatant contains platelet-rich plasma and EVs (MVs and exosomes). This is followed by a further centrifugation at $13000 \times \boldsymbol{g}$ for 30 min to pellet the platelets, with the remaining EVs in the platelet poor plasma (PPP) supernatant. PPP may be snap frozen at $-80^{\circ} \mathrm{C}$ until analysis, or analysed immediately, using one of the methods outlined below. For further purification the PPP can be centrifuged at $17000 \times \boldsymbol{g}$ to pellet the larger MVs, which can then be used for analysis. The supernatant can also be further ultracentrifuged at $100000 \times \boldsymbol{g}$ to pellet the remaining EVs (Thery et al. 2006). Although the resultant EVs are sometimes referred to as exosomes, this population is not completely pure and in addition to exosomes is likely to contain MVs and possibly lipoproteins. Density gradient centrifugation may be used to further purify the exosomal population (Thery et al. 2006), but recent evidence suggests that this still does not completely remove contamination by lipoproteins. Several newer methods have recently been described using commercially available columns and magnetic separation techniques, either directly from plasma or after initial ultracentrifugation to pellet the EV fraction, typically based on CD9 or CD63, but a consensus has not yet developed on which technique is the most promising.

Several companies produce reagents designed to precipitate exosomes from plasma or tissue culture medium, though purity using these techniques is generally low, particularly from plasma. Affinity purification using antibodies bound to columns or beads results in much higher purity of EVs but by definition selectively purifies only EVs expressing the marker protein of interest. Size-exclusion chromatography is increasingly popular as a technique to purify exosomes, having been demonstrated to result in isolates relatively pure of contaminating lipoproteins and protein complexes (Boing et al. 2014, Welton et al. 2015). Alternatively, new approaches on the horizon include the use of antibody arrays to directly identify and quantify exosomes in body fluids bypassing the need for purification all together (Jorgensen et al. 2015).

Since the results of EV isolation procedures may vary, it is important to characterize the particular population being used as much as possible.

\section{Methods for the identification and characterization of EVs}

The small size of EVs makes their identification a challenge, indeed until relatively recently they were considered to be debris and not of any functional significance. Use of electron microscopy enables accurate sizing of all different classes of EVs, and is the gold standard to demonstrate presence of EVs, however this method is time consuming, not quantitative and not suitable for phenotyping (Fig. 3; for review of methodology see (van der Pol et al. 2010)). Other non-optical methods have been used, notably atomic force microscopy, which enables accurate size detection and can also be used in after antibody labeling of vesicles enabling phenotyping. Once again, however, the technique is time consuming and requires concentration of the sample meaning that it is not quantitative. A number of optical methods have been used for detection of EVs, the most widely reported of which is flow cytometry, however detection is limited to particle sizes above $\sim 200 \mathrm{~nm}$, so exosome analysis is not possible with standard configurations and techniques. However, recent exciting developments have enabled direct visualization and characterization of MVs in whole blood, platelet-rich and platelet-free plasma using Image stream technology (Headland et al. 2014).

A number of sophisticated protocols have been described to differentiate MVs from background noise during detection using this method, and standardised guidelines have now been published for optimized collection of plasma for detection of MVs (Lacroix et al. 2012). Techniques are being developed which may even allow the detection of individual exosomes using dedicated flow cytometers with special labelling methods (Pospichalova et al. 2015). An alternative and more widespread approach is to bind exosomes to carrier latex beads, which are easily detectable by flow cytometry (Thery et al. 2006) (Fig. 3).

Published by Bioscientifica Ltd 

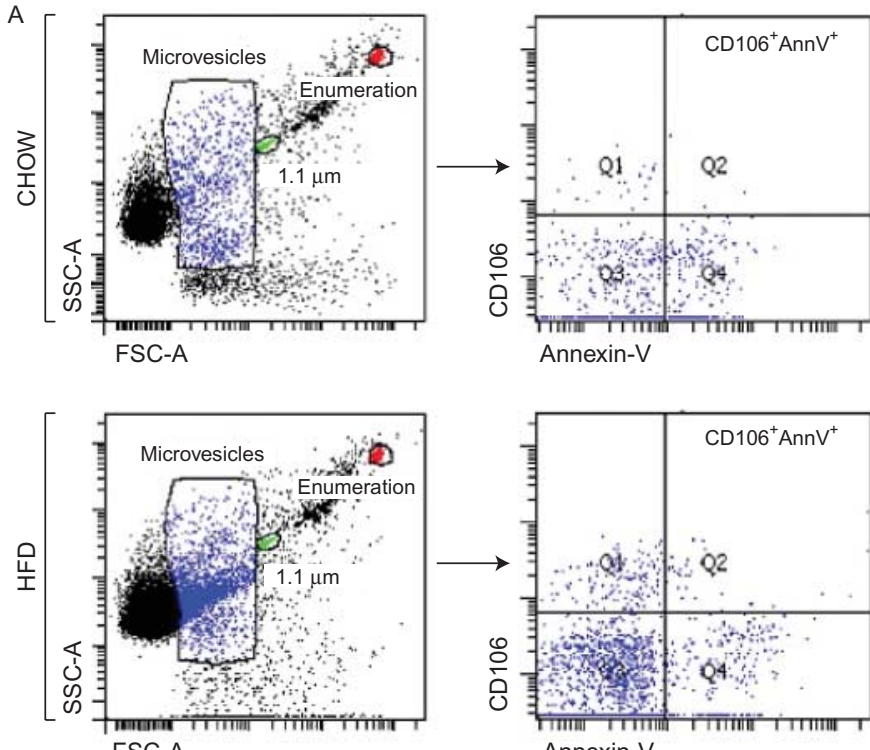

FSC-A

C
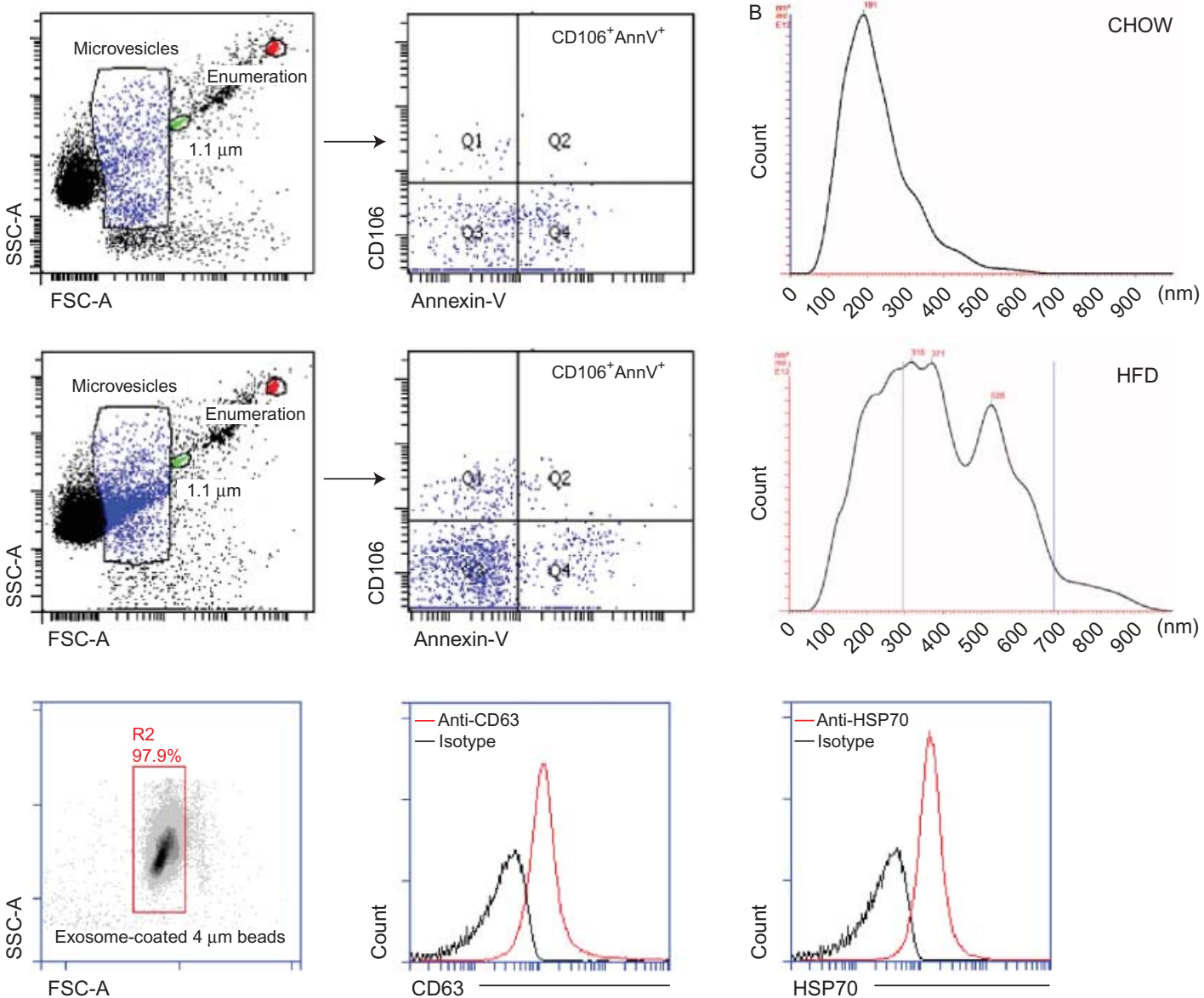

E
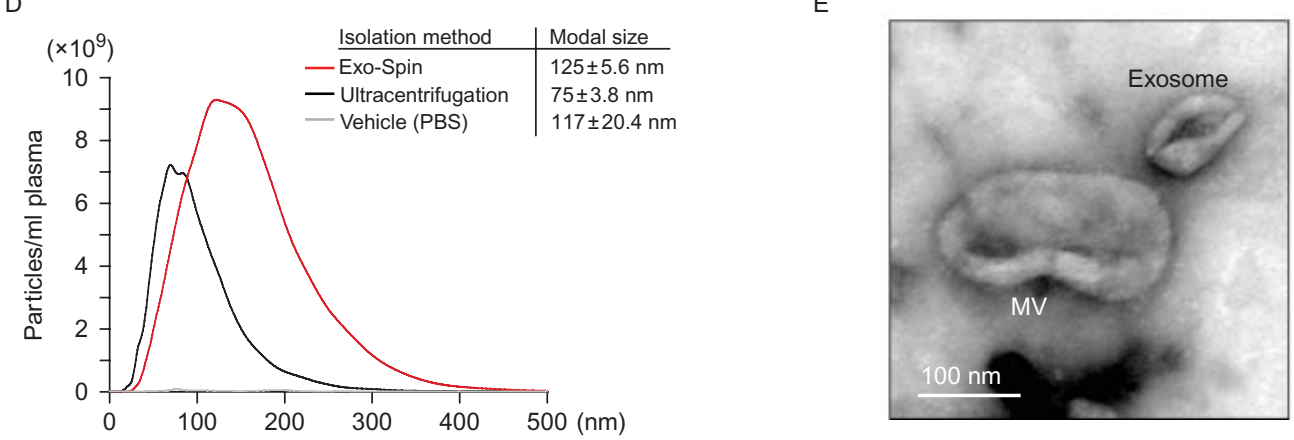

Figure 3

Flow cytometry (FCM) allows direct analysis of microvesicles (MVs) and indirect (conjugated) analysis of exosomes. Nanoparticle tracking analysis (NTA) is the preferred technique for EV quantitation. Electron microscopy (EM) is the golden standard for EV visualization. (A) Direct flow cytometric analysis of MVs in plasma of rats fed chow or high fat diets (HFD; Heinrich et al. 2015) after staining for phosphatidyl serine exposure (Annexin V PE-Cy7.7) and CD106 (PE) to determine MV release from activated endothelial cells. Enumeration beads

Important considerations for detection of MVs by flow cytometry are that accurate sizing and enumeration of the MV population may be hampered by the light scattering of small particles compared with larger cells, for which flow (red) and $1.1 \mu \mathrm{m}$ sizing beads (green) were added as internal controls. (B) NTA of MVs from rats fed chow or HFD. (C) Indirect flow cytometric analysis of exosomes bound to aldehyde sulphate beads $(4 \mu \mathrm{m})$ after staining for the tetraspannin CD63 and surface HSP70 (Vicencio et al. 2015). (D) NTA of human plasma exosomes isolated via ultraceintrifugation (black line) or using the Exo-spin (Cell Guidance Systems, Cambridge, United Kingdom) commercial kit (red line). (E) Electron micrograph of MVs and exosomes.

cytometers are usually used. However, inclusion of commercially available pre-calibrated counting beads in all samples as internal controls and use of sizing beads can enable standardisation of measurements between samples

Published by Bioscientifica Ltd. 
in the same study (Fig. 3) - although caution should be used when directly comparing data from flow cytometry with other methods of counting MV. The newer generations of flow cytometers have been optimized to enable detection of smaller particles. The use of surface markers for phenotyping MV has been reviewed elsewhere (Macey et al. 2011, Lacroix \& Dignat-George 2012).

Flow cytometry (FCM) is very useful for detection of different phenotypic markers on the surface of MVs and enables accurate characterisation of the source of circulating EVs in bodily fluids, however this technique is not suitable for detection of smaller exosomes and several alternative methodologies have been developed, each with its own instrumentation. These include dynamic light scattering, nanoparticle tracking analysis (NTA, Fig. 3), and tunable resistive pulse sensing (van der Pol et al. 2010). These methods have greater size discrimination compared with flow cytometry (down to below $50 \mathrm{~nm}$ diameter) and so enable quantitation of exosomes and smaller MV more efficiently (cost and time) than by EM or atomic force microscopy, however, they are limited by lack of multiple laser capabilities to enable accurate phenotyping, as well as sometimes requiring lengthy purification protocols to ensure that only exosomes are quantified. Importantly, they cannot distinguish EVs from other particulate matter such as protein aggregates, so confirmatory techniques are required to validate $\mathrm{EV}$ presence. Raman spectroscopy has also been used to define $\mathrm{EV}$ populations. This is a highly sensitive technique for analysis of the biochemical composition of EVs without labelling, and can provide quantitative data, however it is very time consuming. Direct detection of marker proteins on exosomes is challenging using these techniques.

\section{EVs can transfer proteins and RNA}

The field of EV research was greatly invigorated by the demonstration that they are able to deliver proteins and RNA to recipient cells. The first evidence for this was obtained in platelets, which released tissue factor (TF), which was subsequently functionally transferred via MVs to monocytes and other cells where TF was able to exert its biological effects (Scholz et al. 2002, Del Conde et al. 2005). MVs from tumour cells were shown to be capable of transferring a truncated, oncogenic form of the epidermal growth factor receptor between cells, activating signalling pathways (MAPK and Akt) and thereby transferring the associated transformed phenotype (Al-Nedawi et al. 2008). MVs can also deliver mRNA (Skog et al. 2008).
Exosomes can also deliver molecules into the membrane of recipient cells. This appears to be part of their normal function in helping to establish morphogen gradients during development. For example, exosomes can transfer the Notch ligand Delta-like 4 between endothelial cells, where it is incorporated into the membrane of the target endothelial cells, and inhibits Notch signalling altering angiogenesis (Sheldon et al. 2010). Interestingly, some cytoprotective proteins have been shown to be transferred between cells. $\alpha \mathrm{B}$ crystallin is secreted from human retinal pigment epithelium in exosomes, and taken up by adjacent photoreceptors, protecting them from oxidative stress (Sreekumar et al. 2010).

In a seminal paper, Valadi et al. (2007), were first to show that exosomes can also transfer mRNA and miRNA between cells. In this study, mast cells were demonstrated to transfer functional mRNAs between cells that were subsequently translated. Importantly when exosomes were pre-treated with RNAse and trypsin, the effect was no longer observed, demonstrating that the mRNA was protected within the vesicles and not simply associated or co-purified.

The profile of miRNAs contained within exosomes appears to depend on the cell type of origin. The miRNA profile is different in exosomes released from $\mathrm{C} 2 \mathrm{C} 12$ myoblasts compared with those released by $\mathrm{C} 2 \mathrm{C} 12$ cells once they have differentiated into myotubes (Forterre et al. 2014). The miRNA profile within exosomes was also found to differ from the parent $\mathrm{C} 2 \mathrm{C} 12$ cells, which indicates that there is selective sorting of miRNA into exosomes (Forterre et al. 2014). The mechanism for this is only beginning to be unravelled, but appears to involve recognition of particular sequence motifs by sumoylated heterogeneous nuclear ribonucleoprotein A2B1 (Villarroya-Beltri et al. 2013). When the exosomes secreted by C2C12 myotubes were taken up by myoblasts they suppressed expression of Sirt1, potentially modulating metabolic homeostasis and the commitment of myoblasts during differentiation (Forterre et al. 2014).

There is also evidence that exosomes are used by some cells in the heart to communicate to each other. Cardiac fibroblasts secrete exosomes that are enriched in specific miRNAs, including miR-21-3p. Intriguingly, this particular miRNA is a 'passenger strand' miRNA which normally undergoes intracellular degradation and was therefore believed to be non-functional (Bang et al. 2014). However, when neonatal cardiomyocytes took up these exosomes, they increased in size indicating a hypertrophic response (Bang et al. 2014). Endothelial cells have also been shown to transfer miRNA via EVs, in this case transferring EV to

Published by Bioscientifica Ltd 
smooth muscle cells after stimulation by shear stress, which is known to be atheroprotective (Hergenreider et al. 2012). The EVs delivered functional miR-143/145 into smooth muscle cells in co-culture, which controlled the expression of target genes (Hergenreider et al. 2012). Importantly, when administered in vivo to $\operatorname{ApoE}(-/-)$ mice, they reduced atherosclerotic lesion formation in the aorta (Hergenreider et al. 2012). The vesicles in this study were referred to conservatively as 'EVs,' because a maximum centrifugation speed of $20500 \times \boldsymbol{g}$ was used to pellet them, and the size range of most of the vesicles on electron micrographs ranged between 60 and $130 \mathrm{~nm}$, therefore they likely contained a mix of exosomes and MVs.

In view of the RNA content of EVs which is related to the cell type of origin, and can alter in pathological settings, they have become an attractive source of biomarkers for profiling and identification of disease markers (Jansen et al. 2013, Cheng et al. 2014, Kruger et al. 2014), as has been reviewed elsewhere (Gaceb et al. 2014).

\section{The role of EVs in diabetes and metabolic disease}

T2DM is characterized by elevated fasting plasma glucose levels combined with insulin resistance. The metabolic syndrome additionally comprises abdominal (central) obesity, high blood pressure, insulin resistance, and lipid abnormalities (Perrone-Filardi et al. 2015). It is present in $34 \%$ of the population, and greatly increases the risk of heart failure (Perrone-Filardi et al. 2015). There is accumulating evidence that EVs are elevated in these conditions and can contribute to some of the pathophysiology, including vascular complications, inflammation, and alterations in blood coagulation (recent review Lakhter \& Sims (2015)).

Exosomes and MVs from different cellular sources can be identified constitutively in plasma from normal individuals (Caby et al. 2005, Raposo \& Stoorvogel 2013), including MVs released from monocytes, lymphocytes, endothelial cells, erythrocytes, and platelets. A number of studies have demonstrated that the numbers of circulating MVs is increased in insulin-resistant patients (Jayachandran et al. 2011), and in patients with T2DM (Omoto et al. 1999, Diamant et al. 2002). Levels are further increased in those with microvascular complications (Omoto et al. 1999, Ogata et al. 2006), or secondary macrovascular CVD, including atherosclerosis (Diamant et al. 2002). Increased numbers of MV have also been linked to obesity (Stepanian et al. 2013). Interestingly, a significant reduction in MV numbers has been described after calorific restriction or bariatric surgery in these patients (Cheng et al. 2013). Increased EVs are also a hallmark of CVD including atherosclerosis (Feng et al. 2010), hypertension (Chen et al. 2012), and following stroke or myocardial infarction (D'Alessandra et al. 2010, Kim et al. 2012).

The role of chronic inflammation in progression of CVD and CMD has been highlighted in a number of studies (reviewed in Hansson et al. (2015) and Lindhardsen et al. (2015)) and circulating EVs are increased in many inflammatory conditions (e.g., (Joop et al. 2001, Daniel et al. 2006, Suades et al. 2015)). Their role in propagation of endothelial pro-inflammatory cascades is also increasingly recognized and was first described by Mesri and Altieri. They stimulated EVs in vivo in healthy volunteers by infusion of a chemotactic peptide and showed that these were able to induce cytokine and chemokine release from endothelial cells in vitro (Mesri \& Altieri 1998). A number of other studies have reported similar findings using EVs from patients or animal models (Meziani et al. 2010, Wang et al. 2011). We have recently shown that EVs induced by long term feeding of a high fat diet in a rat model of insulin resistance and T2DM were able to induce VCAM-1 adhesion molecule expression and ROS production in rat cardiac endothelial cells in vitro (Heinrich et al. 2015).

The same factors that increase the risk of cardiometabolic disease are also risk factors for polycystic ovary syndrome (PCOS) (Daskalopoulos et al. 2015), the most common endocrine disorder in women aged 18-44, affecting up to $10 \%$ of the population, and which leads to reduced fertility (Teede et al. 2010). Several studies have now shown that in accordance with these increased risk factors, PCOS patients have increased circulating levels of EVs, particularly pro-coagulant platelet MVs (Koiou et al. 2011, Koiou et al. 2013). Willis et al. (2014) recently measured increased numbers of circulating EVs nearing the exosome size range $(<150 \mathrm{~nm})$, with a greater percentage of annexin $\mathrm{V}^{+\mathrm{ve}} \mathrm{MV}$ and 16 miRNA that were differentially expressed compared with matched controls. However, a causal relationship has not yet been established between MVs and the other symptoms of PCOS which include excess androgen activity, oligo-ovulation or anovulation, and polycystic ovaries (Teede et al. 2010).

\section{The role EVs in the function and dysfunction of healthy and diseased endothelium}

A number of studies have demonstrated a correlation between the number of circulating endothelial $\left(\mathrm{CD} 31^{+} \mathrm{CD} 41^{-}\right) \mathrm{MVs}$ and endothelial dysfunction in

Published by Bioscientifica Ltd. 
patients with coronary artery disease (Chen et al. 2012, Wang et al. 2014a, Werner et al. 2006). Similarly, in T2DM patients higher numbers of endothelial MVs correlate with impaired endothelium function, as determined by the measurement of flow mediated dilatation in the brachial artery (Feng et al. 2010). In addition to their levels increasing with endothelial dysfunction, MVs may also have a direct effect on endothelial function. MVs isolated from T2DM patients by centrifugation have been shown to impair shear stress induced dilatation of mouse mesenteric arteries (Martin et al. 2004) while aortic ring experiments have shown that endothelial derived EVs (obtained by ultracentrifugation at $100000 \times \boldsymbol{g}$ ) decrease nitric oxide (NO) and increase reactive oxygen species production, as well as impairing acetylcholine-mediated vasorelaxation (Brodsky et al. 2004). Consequently, MVs have gained some notoriety as potentially detrimental factors contributing to CVD.

On the other hand, EVs have also been observed to have some beneficial effects, particularly with regards to the stimulation of endothelial proliferation, migration, and tube formation in vitro (Deregibus et al. 2007, Vrijsen et al. 2010, Jansen et al. 2013). This effect has been observed with EVs isolated from apoptotic endothelial cells (Deregibus et al. 2007, Jansen et al. 2013) (and therefore presumably containing many apoptotic vesicles), as well as with more pure populations of MVs isolated from platelets (Kim et al. 2004, Brill et al. 2005), from endothelial progenitor cells (Deregibus et al. 2007, Vrijsen et al. 2010), or from ischemic muscle (Leroyer et al. 2009). Exosomes isolated from cardiomyocyte progenitor cells (Vrijsen et al. 2010) or the conditioned medium of bone marrow $\mathrm{CD}_{4} 4^{+}$stem cells (Sahoo et al. 2011) have been shown to have a similar effect on endothelial cell proliferation and migration.

EVs can also stimulate endothelial repair. For example, endothelial EVs were isolated by centrifugation from human coronary artery endothelial cells undergoing apoptosis. When administered to mice in which a region of endothelium had been denuded, these EVs were found to be capable of repairing the endothelium via delivery of miR-126 (Jansen et al. 2013). It is significant, however, that this effect was abrogated in EVs isolated from cells which had been grown under hyperglycaemic conditions in vitro or isolated from patients with T2DM, since this suggests that this reparative property of EVs is altered by diabetes and may contribute to continued vascular damage and dysfunction (Jansen et al. 2013). Similarly, exosomes from the cardiomyocytes of non-diabetic rats were founds to be pro-angiogenic, stimulating endothelial proliferation, migration, and tube formation in vitro, while those isolated from the cardiomyocytes of diabetic rats had the opposite effect (Wang et al. 2014b).In this example, the detrimental effect was attributed to exosomal transfer of miR-320 and the down-regulation of its target genes (IGF-1, Hsp20, and Ets2) (Wang et al. 2014b).

Various additional mechanisms have been implicated in the stimulatory effect of exosomes on endothelial cells. Platelet MVs appear to activate pro-angiogenic ERK and PI3K/Akt pathways (Kim et al. 2004, Brill et al. 2005) and may contain a contain a lipid growth factor (Kim et al. 2004), while EVs from endothelial progenitor cells appear to transfer mRNAs that activate PI3K/AKT and eNOS signaling in the recipient endothelial cells (Deregibus et al. 2007). The transfer of miR-214 has also been proposed to mediate induction of angiogenesis by endothelial exosomes by suppressing the expression of ATM in recipient cells (van Balkom et al. 2013). Endothelial cells also communicate atheroprotective stimuli to smooth muscle cell via the transmission of miR-143/145 via EVs (Hergenreider et al. 2012). In this study, EV were purified by centrifugation at $20500 \boldsymbol{g}$ for $1 \mathrm{~h}$, resulting in vesicles that were mostly between 60 and $130 \mathrm{~nm}$.

In some cases, exosomes can also suppress hyperproliferative pathways such as those that contribute to hypoxia-induced pulmonary hypertension. Here, the beneficial effect of mesenchymal stromal cells was shown to be mediated by the release of exosomes which suppressed hyperproliferative pathways including those mediated by STAT3 and the miR-17 superfamily, in addition to increasing lung levels of miR-204 (Lee et al. 2012).

Recently, pressure overload or stretch was shown to cause the release from cardiomyocytes of exosomes containing functional angiotensin II type 1 receptors, which are able to be transferred to skeletal muscle, mesenteric resistance vessels and cardiomyocytes, conferring responsiveness to angiotensin II (Pironti et al. 2015). This exciting data suggest that exosomes may contribute to the in vivo tissue distribution of cell surface receptors such as angiotensin II, with functional consequences for the cardiovascular system.

\section{The role of EVs in coagulopathies}

When EVs were first described by Peter Wolf they were referred to as 'platelet dust' (Wolf 1967) because they were thought not to be functionally significant. Despite there being some reports to the contrary (Tushuizen et al. 2012), numerous studies have shown that platelet EVs are

Published by Bioscientifica Ltd. 
procoagulant due to the exposure of negatively charged PS which can enhance clot formation (for review see Hargett \& Bauer (2013)). Indeed, platelet EVs have more binding sites for the factors involved in the clotting cascade than do activated platelets themselves (Sinauridze et al. 2007). More recent studies have revealed the presence of TF on the surface of endothelial- and monocyte-derived EVs (Breitenstein et al. 2010), as well as P-selectin glycoprotein ligand-1 which can bind to P-selectin on the surface of activated platelets and become incorporated into the clot (Falati et al. 2003). Other receptors including glycoprotein IIb/IIIa (Sommeijer et al. 2005), factor VIII, factor Va (Nomura et al. 1993) and protein disulphide isomerase (Raturi et al. 2008) may also be present on the surface of EVs and participate in clot formation and thrombosis.

In addition to hyperglycemia, hyperinsulinemia can cause an increase in procoagulant TF-positive MVs (Boden \& Rao 2007), and MVs are elevated in otherwise-healthy individuals with signs of metabolic syndrome (Agouni et al. 2008, Ueba et al. 2008). A correlation between circulating endothelial microvesicles and CMR factors (particularly dyslipidaemia), was also detected in the Framingham Heart Study cohort (Amabile et al. 2014). The presence of hypertension, elevated triglycerides, and metabolic syndrome all increased circulating MVs, but dyslipidaemia had the most severe effect. Obesity has also been correlated with increased circulating endothelial MVs in children (Gunduz et al. 2012). These increases may contribute to the disease, since MVs from individuals with metabolic syndrome have been shown to impair endothelium-dependent relaxation and decrease endothelial NO synthase expression when injected into mice (Agouni et al. 2008). Other cardiovascular risk factors such as uremia may also correlate with increased numbers of platelet MVs which may trigger thrombosis (Ando et al. 2002). Elevated uric acid in chronic renal failure patients may also contribute to their increased risk of cardiovascular events (Faure et al. 2006).

Tsimerman et al. (2011) measured increased numbers of pro-coagulant TF-positive EVs in patients with T2DM, but MV coagulability was significantly increased only in those who also had macrovascular complications (foot ulcers and coronary artery disease). EVs were isolated and evaluated for their ability to induce tube formation in endothelial cells in vitro. Endothelial tube formation was stimulated by MVs from healthy controls, but was defective when incubated with MVs from patients with macrovascular complications (Tsimerman et al. 2011).

Thus, hyperglycemia, dyslipidaemia, and hyperinsulinemia as well as hyperuricemia and uremia appear to contribute to cardiometabolic disease via the procoagulant activity of MVs, but also due to their diminished ability to support endothelial function.

\section{EVs as a potential therapy for cardiometabolic disease}

The heart is essentially terminally differentiated, meaning that there is very little division of cardiomyocytes after injury (e.g., IR), and instead those that remain tend to undergo a compensatory increase in size. The possibility of renewing the cardiomyocytes by stem cell therapy has been intensively investigated for a number of years, however, the results of this approach have been largely disappointing. Some improvements in cardiac function have been observed after stem cell therapy, although this is generally acknowledged to occur in the absence of new cardiomyocyte formation. Interestingly, similar levels of benefit could also be obtained experimentally after injecting medium that had been conditioned by stem cells. It was therefore proposed that stem cells release cytokines, growth factors, and other proteins in a 'paracrine' manner to improve survival and function of cardiomyocytes (Yoon et al. 2005, Menasche 2015, Yu et al. 2015).

In 2010, it was shown that exosomes purified from the conditioned medium of human ESC-derived mesenchymal stem cells (ESC-MSC) by HPLC size-exclusion fractionation, could protect the heart both in vitro and in vivo (Lai et al. 2010). Cardiac function after 28 days was also improved (Arslan et al. 2013). An increase in the activity of cardioprotective kinases Akt and GSK3 $\alpha / \beta$ was observed $1 \mathrm{~h}$ after exosome administration until the following day (Arslan et al. 2013). These kinases are known to be highly cardioprotective (Hausenloy et al. 2005). In another study, exosomes were isolated from MSC cells overexpressing GATA4, and these also restored cardiac contractile function and reduced infarct size when injected into rat hearts at the time of infarction (Yu et al. 2015). Protection was attributed to an increase in the treated hearts of miR-19a, which targets PTEN, indirectly increasing Akt and ERK activation. However, with such experiments it is difficult to ascertain whether the miR-19a was transferred from the MSC exosomes or was a transcriptional response of the myocardium to the treatment (Yu et al. 2015). The ability to activate protective pathways does not appear to be restricted to exosomes, since MVs derived from human adult mesenchymal stem cells were also able to protect the kidney against ischaemia and reperfusion injury (Gatti et al. 2011).

Published by Bioscientifica Ltd. 
MSC are not the only type of stem cell that has been shown to release exosomes with beneficial cardiovascular effects. Intramyocardial injection of exosomes from murine cardiac progenitor cells (CPCs) reduced apoptosis after ischaemia and reperfusion (Chen et al. 2013). In this study, however, exosomes were isolated by precipitation with polyethylene glycol (PEG) (Chen et al. 2013), which raises some uncertainty about the effects that the PEG might have itself. In another study EVs were isolated from CPCs derived from atrial appendage explants from patients undergoing heart valve surgery (Barile et al. 2014). Injection of these CPCs-EVs into the hearts of rats subject to permanent coronary artery ligation reduced cardiomyocyte apoptosis and scar size, increased the amount of viable tissue in the infarct area, increased blood vessel density, and prevented the impairment of ventricular function between day 2 and day 7 (Barile et al. 2014). In contrast, exosomes isolated from normal human dermal fibroblasts exhibited no benefit, suggesting that effects depend on cell type of origin (Barile et al. 2014). Intramyocardial injection of exosomes isolated from CPCs that had been exposed to hypoxia for $12 \mathrm{~h}$ improved cardiac function and also reduced fibrosis 21 days (Gray et al. 2015). The exosomes released after hypoxia had an altered miRNA content, and co-regulated miRNA with a beneficial profile were identified (Gray et al. 2015). Although cardiac endothelial cells and fibroblasts took up fluorescently stained exosomes in vitro, uptake was minimal in primary rat cardiomyocytes (Gray et al. 2015), suggesting either that they deliver miRNA directly to the former cells types, or that they interact with surface receptors on cardiomyocytes without delivering miRNA intracellularly. Thus, the exact mechanism of functional benefit conferred by CPC-EVs remains unclear.

When a nonviral mini-circle plasmid carrying HIF1, a transcription factor that mediates adaptive responses to ischemia, was delivered into the endothelium of ischemic mouse myocardium, these cells were found to release exosomes with a higher content of miR-126 and miR-210. These exosomes could be taken up by CPCs administered to the heart, leading to the activation of pro-survival kinases and to a switch towards glycolysis. This resulted in them having an increased tolerance against hypoxic stress (Ong et al. 2014) and suggests the interesting possibility that endothelial cells can support CPC survival by exosomal transfer of miRNA.

An attractive aspect of using EVs for therapy is the potential for altering their cargo to augment their protective capabilities. In a study by Mackie et al. (2012), $\mathrm{CD} 4^{+}$cells or their exosomes showed no benefit after injection into ischaemic mouse hearts. However, CD34 ${ }^{+}$ cells were then genetically modified to to express the sonic hedgehog (Shh) protein, in order to enhance the angiogenic quality of $\mathrm{CD} 34^{+}$cells. When $\mathrm{CD} 34^{+}$Shh cells were injected into the infarct border zone in mice, infarct size was reduced, border zone capillary density was increased, and ventricular dilation and cardiac function were improved 4 weeks later. In vitro studies in cells were performed to demonstrate that Shh was released from the $\mathrm{CD} 34^{+}$Shh cells in exosomes and could be transferred to recipient cells and (modestly) activate transcription. Injection of the exosomes from $\mathrm{CD} 34^{+} \mathrm{Shh}$ cells had the same benefit, though exosomes from $\mathrm{CD}_{3} 4^{+}$cells wihout Shh showed no benefit (Mackie et al. 2012).

Strikingly, it has been shown that there are on the order of $10^{10} \mathrm{EVs}$ per $\mathrm{ml}$ present in the blood of all individuals, after isolation using the technique of differential ultracentrifugation, (Caby et al. 2005), and these could potentially be continually delivering different miRNA or receptor-ligand mediated signals to the heart. This possibility was addressed by isolating plasma exosomes from rats or healthy individuals by differential ultracentrifugation and testing whether they were cardioprotective in in vitro, ex vivo, and in vivo models of IR (Vicencio et al. 2015). Indeed, exosomes from plasma were strongly cardioprotective, activating the cardioprotective ERK1/2 kinase and reducing infarct size (Vicencio et al. 2015). Plasma exosomes were similarly protective in an isolated perfused rat heart model and in primary cardiomyocytes, suggesting a direct effect of the exosomes at the plasma membrane level, although interestingly exosomes did not appear to be taken up by the cardiomyocytes but they were endocytosed by endothelial cells (Vicencio et al. 2015). This study also showed that the number of exosomes in the plasma was increased by short $(5 \mathrm{~min})$ cycles of limb IR. This manipulation is under investigation of a means of inducing protection of the heart and other organs via a phenomenon known as 'remote ischaemic preconditioning (RIC)' (Hausenloy \& Yellon 2008). As yet, the mechanism of RIC is unknown although evidence for several mediators has been presented, including SDF- $1 \alpha$ and Il-10 (Cai et al. 2012, Davidson et al. 2013). As vehicles able to deliver multiple signals between cells, EVs had been proposed as possible candidates for carriers of the cardioprotective factor released by RIC (Yellon \& Davidson 2014). A study by Giricz et al. (2014) suggested that this may be the case, since RIC was not effective when EVs were removed from medium containing the factor. However, in a dose-response experiment conducted using primary adult rat cardiomyocytes the EVs released after RIC were

Published by Bioscientifica Ltd. 
found not to be significantly more protective that exosomes from baseline (Vicencio et al. 2015).

On the other hand, the observation that plasma EVs themselves were cardioprotective is important and may suggest that they signal continuously to the heart, modulating the protective state. Protection was shown to involve HSP70 in the exosome membrane, which binds to TLR4 on cardiomyocytes, activating ERK1/2, p38MAPK, and downstream phosphorylation of the small heat shock protein HSP27 (Vicencio et al. 2015). TLR4 is part of the innate immune system, and strong activation by its ligands from bacteria leads to a cell damage response and can cause cell death. However, mild activation is known to be protective (Mathur et al. 2011, Zhang et al. 2013). Other studies have suggested a link between body fluid exosomes and TLR-dependent signaling pathways, possibly mediating immunosuppressive and anti-inflammatory pathways (Bretz et al. 2013, Zhang et al. 2014).

\section{Conclusion}

With T2DM reaching epidemic proportions and CVD being the major cause of death worldwide, novel therapeutic strategies are urgently needed to offer cell and tissue repair mechanisms to the myocardium and also diseases characterized by endothelial dysfunction. EVs including MVs and exosomes have emerged over the past decade to attract immense interest due to their potential either as biomarkers or mediators of disease. Increased MVs in plasma can be observed in patients with insulin resistance, T2DM, atherosclerosis and also after stroke or myocardial infarct. MVs have been also described as mediators of inflammation and to be involved in the pro-coagulant actions of platelets. The protein or RNA cargo of EVs offers additional potential not only for their use as biomarkers but also for their use as vehicles for delivering bioactives. As such, they offer the capability of delivering multiple signals to target tissues. Stem cells are the best-explored example of cells that deliver miRNA via exosomes with beneficial effects on the heart, kidneys, and the endothelium. Exosomes and MVs have also been implicated in protecting the heart from infarction and have been proposed as potential mediators of ischaemic conditioning. EVs therefore represent one of the most exciting and promising research areas for the endocrine community. However, there is still much left to understand regarding the mechanisms of $\mathrm{EV}$ formation and their specific targeting to a selective tissue. Although current research has provided valuable insight to the mechanisms of EV release, we are only beginning to understand mechanisms of RNA/protein loading into exosomes for instance, and exploring these mechanisms is essential to design efficient therapeutical strategies involving EVs.

\section{Declaration of interest}

The authors declare that there is no conflict of interest that could be perceived as prejudicing the impartiality of the research reported.

\section{Funding}

This work was funded by a grant from the Medical Research Council (MR/K002066/1) and the British Heart Foundation (RG/08/015/26411).

\section{References}

Agouni A, Lagrue-Lak-Hal AH, Ducluzeau PH, Mostefai HA, Draunet-Busson C, Leftheriotis G, Heymes C, Martinez MC \& Andriantsitohaina R 2008 Endothelial dysfunction caused by circulating microparticles from patients with metabolic syndrome. American Journal of Pathology 173 1210-1219. (doi:10.2353/ajpath. 2008.080228)

Al-Nedawi K, Meehan B, Micallef J, Lhotak V, May L, Guha A \& Rak J 2008 Intercellular transfer of the oncogenic receptor EGFRvIII by microvesicles derived from tumour cells. Nature Cell Biology 10 619-624. (doi:10.1038/ncb1725)

Amabile N, Cheng S, Renard JM, Larson MG, Ghorbani A, McCabe E, Griffin G, Guerin C, Ho JE, Shaw SY et al. 2014 Association of circulating endothelial microparticles with cardiometabolic risk factors in the Framingham Heart Study. European Heart Journal 35 2972-2979. (doi:10.1093/eurheartj/ehu153)

Ando M, Iwata A, Ozeki Y, Tsuchiya K, Akiba T \& Nihei H 2002 Circulating platelet-derived microparticles with procoagulant activity may be a potential cause of thrombosis in uremic patients. Kidney International 62 1757-1763. (doi:10.1046/j.1523-1755.2002.00627.x)

Arslan F, Lai RC, Smeets MB, Akeroyd L, Choo A, Aguor EN, Timmers L, van Rijen HV, Doevendans PA, Pasterkamp G et al. 2013 Mesenchymal stem cell-derived exosomes increase ATP levels, decrease oxidative stress and activate PI3K/Akt pathway to enhance myocardial viability and prevent adverse remodeling after myocardial ischemia/reperfusion injury. Stem Cell Research 10 301-312. (doi:10.1016/j.scr.2013.01.002)

Baietti MF, Zhang Z, Mortier E, Melchior A, Degeest G, Geeraerts A, Ivarsson Y, Depoortere F, Coomans C, Vermeiren E et al. 2012 Syndecan-syntenin-ALIX regulates the biogenesis of exosomes. Nature Cell Biology 14 677-685. (doi:10.1038/ncb2502)

van Balkom BW, de Jong OG, Smits M, Brummelman J, den Ouden K, de Bree PM, van Eijndhoven MA, Pegtel DM, Stoorvogel W \& Wurdinger T 2013 Endothelial cells require miR-214 to secrete exosomes that suppress senescence and induce angiogenesis in human and mouse endothelial cells. Blood 121 3997-4006, S3991-3915. (doi:10.1182/blood-2013-02-478925)

Bang C, Batkai S, Dangwal S, Gupta SK, Foinquinos A, Holzmann A, Just A, Remke J, Zimmer K, Zeug A et al. 2014 Cardiac fibroblast-derived microRNA passenger strand-enriched exosomes mediate cardiomyocyte hypertrophy. Journal of Clinical Investigation 124 2136-2146. (doi:10.1172/JCI70577)

Barile L, Lionetti V, Cervio E, Matteucci M, Gherghiceanu M, Popescu LM, Torre T, Siclari F, Moccetti T \& Vassalli G 2014 Extracellular vesicles from human cardiac progenitor cells inhibit cardiomyocyte apoptosis 
and improve cardiac function after myocardial infarction. Cardiovascular Research 103 530-541. (doi:10.1093/cvr/cvu167)

Boden G \& Rao AK 2007 Effects of hyperglycemia and hyperinsulinemia on the tissue factor pathway of blood coagulation. Current Diabetes Reports 7 223-227. (doi:10.1007/s11892-007-0035-1)

Boing AN, van der Pol E, Grootemaat AE, Coumans FA, Sturk A \& Nieuwland R 2014 Single-step isolation of extracellular vesicles by size-exclusion chromatography. Journal of Extracellular Vesicles $\mathbf{3}$ article 23430. (doi:10.3402/jev.v3.23430)

Breitenstein A, Tanner FC \& Luscher TF 2010 Tissue factor and cardiovascular disease: quo vadis? Circulation Journal 74 3-12. (doi:10.1253/circj.CJ-09-0818)

Bretz NP, Ridinger J, Rupp AK, Rimbach K, Keller S, Rupp C, Marme F, Umansky L, Umansky V, Eigenbrod T et al. 2013 Body fluid exosomes promote secretion of inflammatory cytokines in monocytic cells via Toll-like receptor signaling. Journal of Biological Chemistry $\mathbf{2 8 8}$ 36691-36702. (doi:10.1074/jbc.M113.512806)

Brill A, Dashevsky O, Rivo J, Gozal Y \& Varon D 2005 Platelet-derived microparticles induce angiogenesis and stimulate post-ischemic revascularization. Cardiovascular Research 67 30-38. (doi:10.1016/ j.cardiores.2005.04.007)

Brodsky SV, Zhang F, Nasjletti A \& Goligorsky MS 2004 Endotheliumderived microparticles impair endothelial function in vitro. American Journal of Physiology. Heart and Circulatory Physiology 286 H1910-H1915. (doi:10.1152/ajpheart.01172.2003)

Brunzell JD, Davidson M, Furberg CD, Goldberg RB, Howard BV, Stein JH \& Witztum JL 2008 Lipoprotein management in patients with cardiometabolic risk: consensus conference report from the American Diabetes Association and the American College of Cardiology Foundation. Journal of the American College of Cardiology 51 1512-1524. (doi:10.1016/j.jacc.2008.02.034)

Caby MP, Lankar D, Vincendeau-Scherrer C, Raposo G \& Bonnerot C 2005 Exosomal-like vesicles are present in human blood plasma. International Immunology 17 879-887. (doi:10.1093/intimm/dxh267)

Cai ZP, Parajuli N, Zheng X \& Becker L 2012 Remote ischemic preconditioning confers late protection against myocardial ischemiareperfusion injury in mice by upregulating interleukin-10. Basic Research in Cardiology 107 277. (doi:10.1007/s00395-012-0277-1)

Chen Y, Feng B, Li X, Ni Y \& Luo Y 2012 Plasma endothelial microparticles and their correlation with the presence of hypertension and arterial stiffness in patients with type 2 diabetes. Journal of Clinical Hypertension 14 455-460. (doi:10.1111/j.1751-7176.2012.00631.x)

Chen L, Wang Y, Pan Y, Zhang L, Shen C, Qin G, Ashraf M, Weintraub N, Ma G \& Tang Y 2013 Cardiac progenitor-derived Exosomes protect ischemic myocardium from acute ischemia/reperfusion injury. Biochemical and Biophysical Research Communications 431 566-571. (doi:10.1016/j.bbrc.2013.01.015)

Cheng V, Kashyap SR, Schauer PR, Kirwan JP \& McCrae KR 2013 Restoration of glycemic control in patients with type 2 diabetes mellitus after bariatric surgery is associated with reduction in microparticles. Surgery for Obesity and Related Diseases 9 207-212. (doi:10.1016/j.soard.2011.09.026)

Cheng L, Sharples RA, Scicluna BJ \& Hill AF 2014 Exosomes provide a protective and enriched source of miRNA for biomarker profiling compared to intracellular and cell-free blood. Journal of Extracellular Vesicles 3 article 23743. (doi:10.3402/jev.v3.23743)

Colombo M, Raposo G \& Thery C 2014 Biogenesis, secretion, and intercellular interactions of exosomes and other extracellular vesicles. Annual Review of Cell and Developmental Biology 30 255-289. (doi:10.1146/annurev-cellbio-101512-122326)

D’Alessandra Y, Devanna P, Limana F, Straino S, Di Carlo A, Brambilla PG, Rubino M, Carena MC, Spazzafumo L \& De Simone M 2010 Circulating microRNAs are new and sensitive biomarkers of myocardial infarction. European Heart Journal 31 2765-2773. (doi:10.1093/eurheartj/ehq167)

Daniel L, Fakhouri F, Joly D, Mouthon L, Nusbaum P, Grunfeld JP, Schifferli J, Guillevin L, Lesavre P \& Halbwachs-Mecarelli L 2006
Increase of circulating neutrophil and platelet microparticles during acute vasculitis and hemodialysis. Kidney International 69 1416-1423. (doi:10.1038/sj.ki.5000306)

Daskalopoulos G, Karkanaki A, Piouka A, Prapas N, Panidis D, Gkeleris P \& Athyros VG 2015 Excess metabolic and cardiovascular risk is not manifested in all phenotypes of polycystic ovary syndrome: implications for diagnosis and treatment. Current Vascular Pharmacology 13 788-800. (doi:10.2174/1567201812666150120163025)

Davidson SM, Selvaraj P, He D, Boi-Doku C, Yellon RL, Vicencio JM \& Yellon DM 2013 Remote ischaemic preconditioning involves signalling through the SDF-1 $\alpha /$ CXCR4 signalling axis. Basic Research in Cardiology 108 377. (doi:10.1007/s00395-013-0377-6)

Del Conde I, Shrimpton CN, Thiagarajan P \& Lopez JA 2005 Tissuefactor-bearing microvesicles arise from lipid rafts and fuse with activated platelets to initiate coagulation. Blood 106 1604-1611. (doi:10.1182/blood-2004-03-1095)

Deregibus MC, Cantaluppi V, Calogero R, Lo Iacono M, Tetta C, Biancone L, Bruno S, Bussolati B \& Camussi G 2007 Endothelial progenitor cell derived microvesicles activate an angiogenic program in endothelial cells by a horizontal transfer of mRNA. Blood $1102440-2448$. (doi:10.1182/blood-2007-03-078709)

Diamant M, Nieuwland R, Pablo RF, Sturk A, Smit JW \& Radder JK 2002 Elevated numbers of tissue-factor exposing microparticles correlate with components of the metabolic syndrome in uncomplicated type 2 diabetes mellitus. Circulation 106 2442-2447. (doi:10.1161/01.CIR. 0000036596.59665.C6)

Dignat-George F \& Boulanger CM 2011 The many faces of endothelial microparticles. Arteriosclerosis, Thrombosis, and Vascular Biology 31 27-33. (doi:10.1161/ATVBAHA.110.218123)

Falati S, Liu Q, Gross P, Merrill-Skoloff G, Chou J, Vandendries E, Celi A Croce K, Furie BC \& Furie B 2003 Accumulation of tissue factor into developing thrombi in vivo is dependent upon microparticle P-selectin glycoprotein ligand 1 and platelet P-selectin. Journal of Experimental Medicine 197 1585-1598. (doi:10.1084/jem.20021868)

Faure V, Dou L, Sabatier F, Cerini C, Sampol J, Berland Y, Brunet P \& Dignat-George F 2006 Elevation of circulating endothelial microparticles in patients with chronic renal failure. Journal of Thrombosis and Haemostasis 4 566-573. (doi:10.1111/j.1538-7836.2005.01780.x)

Feng B, Chen Y, Luo Y, Chen M, Li X \& Ni Y 2010 Circulating level of microparticles and their correlation with arterial elasticity and endothelium-dependent dilation in patients with type 2 diabetes mellitus. Atherosclerosis 208 264-269. (doi:10.1016/j.atherosclerosis. 2009.06.037)

Forterre A, Jalabert A, Chikh K, Pesenti S, Euthine V, Granjon A, Errazuriz E, Lefai E, Vidal H \& Rome S 2014 Myotube-derived exosomal miRNAs downregulate Sirtuin 1 in myoblasts during muscle cell differentiation. Cell Cycle 13 78-89. (doi:10.4161/cc.26808)

Gaceb A, Martinez MC \& Andriantsitohaina R 2014 Extracellular vesicles: new players in cardiovascular diseases. The International Journal of Biochemistry \& Cell Biology 50 24-28. (doi:10.1016/j.biocel.2014.01.018)

Gatti S, Bruno S, Deregibus MC, Sordi A, Cantaluppi V, Tetta C \& Camussi G 2011 Microvesicles derived from human adult mesenchymal stem cells protect against ischaemia-reperfusion-induced acute and chronic kidney injury. Nephrology, Dialysis, Transplantation 26 1474-1483. (doi:10.1093/ndt/gfro15)

Giricz Z, Varga ZV, Baranyai T, Sipos P, Paloczi K, Kittel A, Buzas E \& Ferdinandy P 2014 Cardioprotection by remote ischemic preconditioning of the rat heart is mediated by extracellular vesicles. Journal of Molecular and Cellular Cardiology 68 75-78. (doi:10.1016/j.yjmcc.2014. 01.004)

Gray WD, French KM, Ghosh-Choudhary S, Maxwell JT, Brown ME, Platt MO, Searles CD \& Davis ME 2015 Identification of therapeutic covariant microRNA clusters in hypoxia-treated cardiac progenitor cell exosomes using systems biology. Circulation Research 116 255-263. (doi:10.1161/CIRCRESAHA.116.304360) 
Gunduz Z, Dursun I, Tulpar S, Bastug F, Baykan A, Yikilmaz A, Patiroglu T, Poyrazoglu HM, Akin L, Yel S et al. 2012 Increased endothelial microparticles in obese and overweight children. Journal of Pediatric Endocrinology \& Metabolism 25 1111-1117. (doi:10.1515/ jpem-2012-0194)

Hansson GK, Libby P \& Tabas I 2015 Inflammation and plaque vulnerability. Journal of Internal Medicine 278 483-493. (doi:10.1111/ joim.12406)

Hargett LA \& Bauer NN 2013 On the origin of microparticles: From "platelet dust" to mediators of intercellular communication. Pulmonary Circulation 3 329-340. (doi:10.4103/2045-8932.114760)

Hausenloy DJ \& Yellon DM 2008 Remote ischaemic preconditioning: underlying mechanisms and clinical application. Cardiovascular Research 79 377-386. (doi:10.1093/cvr/cvn114)

Hausenloy DJ \& Yellon DM 2013 Myocardial ischemia-reperfusion injury: a neglected therapeutic target. Journal of Clinical Investigation 123 92-100. (doi:10.1172/JCI62874)

Hausenloy DJ, Tsang A \& Yellon DM 2005 The reperfusion injury salvage kinase pathway: a common target for both ischemic preconditioning and postconditioning. Trends in Cardiovascular Medicine 15 69-75. (doi:10.1016/j.tcm.2005.03.001)

Headland SE, Jones HR, D'Sa AS, Perretti M \& Norling LV 2014 Cuttingedge analysis of extracellular microparticles using ImageStream(X) imaging flow cytometry. Scientific Reports 4 5237. (doi:10.1038/ srep05237)

Heinrich LF, Andersen DK, Cleasby ME \& Lawson C 2015 Long-term high fat feeding of rats results in increased numbers of circulating microvesicles with pro-inflammatory effects on endothelial cells. British Journal of Nutrition 113 1704-1711. (doi:10.1017/S0007114515001117)

Hergenreider E, Heydt S, Treguer K, Boettger T, Horrevoets AJ, Zeiher AM, Scheffer MP, Frangakis AS, Yin X, Mayr M et al. 2012 Atheroprotective communication between endothelial cells and smooth muscle cells through miRNAs. Nature Cell Biology 14 249-256. (doi:10.1038/ ncb2441)

Hou S, Grillo D, Williams CL, Wasserstrom JA, Szleifer I \& Zhao M 2014 Membrane phospholipid redistribution in cancer micro-particles and implications in the recruitment of cationic protein factors. Journal of Extracellular Vesicles 3 article 22653. (doi:10.3402/jev.v3.22653)

Jansen F, Yang X, Hoelscher M, Cattelan A, Schmitz T, Proebsting S, Wenzel D, Vosen S, Franklin BS, Fleischmann BK et al. 2013 Endothelial Microparticle-Mediated Transfer of MicroRNA-126 Promotes Vascular Endothelial Cell Repair via SPRED1 and Is Abrogated in GlucoseDamaged Endothelial Microparticles. Circulation 128 2026-2038. (doi:10.1161/CIRCULATIONAHA.113.001720)

Jayachandran M, Litwiller RD, Lahr BD, Bailey KR, Owen WG, Mulvagh SL, Heit JA, Hodis HN, Harman SM \& Miller VM 2011 Alterations in platelet function and cell-derived microvesicles in recently menopausal women: relationship to metabolic syndrome and atherogenic risk. Journal of Cardiovascular Translational Research 4 811-822. (doi:10.1007/ s12265-011-9296-9)

Joop K, Berckmans RJ, Nieuwland R, Berkhout J, Romijn FP, Hack CE \& Sturk A 2001 Microparticles from patients with multiple organ dysfunction syndrome and sepsis support coagulation through multiple mechanisms. Thrombosis and Haemostasis 85 810-820.

de Jong OG, Verhaar MC, Chen Y, Vader P, Gremmels H, Posthuma G, Schiffelers RM, Gucek M \& van Balkom BW 2012 Cellular stress conditions are reflected in the protein and RNA content of endothelial cell-derived exosomes. Journal of Extracellular Vesicles 1 article 18396. (doi:10.3402/jev.v1i0.18396)

Jorgensen MM, Baek R \& Varming K 2015a Potentials and capabilities of the extracellular vesicle (EV) array. Journal of Extracellular Vesicles 426048. (doi:10.3402/jev.v4.26048)

Kim HK, Song KS, Chung JH, Lee KR \& Lee SN 2004 Platelet microparticles induce angiogenesis in vitro. British Journal of Haematology 124 376-384. (doi:10.1046/j.1365-2141.2003.04773.x)
Kim SJ, Moon GJ, Cho YH, Kang HY, Hyung NK, Kim D, Lee JH, Nam JY \& Bang OY 2012 Circulating mesenchymal stem cells microparticles in patients with cerebrovascular disease. PLoS ONE 7 e37036. (doi:10.1371/journal.pone.0037036)

Koiou E, Tziomalos K, Katsikis I, Kalaitzakis E, Kandaraki EA, Tsourdi EA, Delkos D, Papadakis E \& Panidis D 2011 Circulating platelet-derived microparticles are elevated in women with polycystic ovary syndrome diagnosed with the 1990 criteria and correlate with serum testosterone levels. European Journal of Endocrinology 165 63-68. (doi:10.1530/ EJE-11-0144)

Koiou E, Tziomalos K, Katsikis I, Papadakis E, Kandaraki EA \& Panidis D 2013 Platelet-derived microparticles in overweight/obese women with the polycystic ovary syndrome. Gynecological Endocrinology 29 250-253. (doi:10.3109/09513590.2012.743005)

Kruger S, Abd Elmageed ZY, Hawke DH, Worner PM, Jansen DA, Abdel-Mageed AB, Alt EU \& Izadpanah R 2014 Molecular characterization of exosome-like vesicles from breast cancer cells. BMC Cancer $\mathbf{1 4}$ 44. (doi:10.1186/1471-2407-14-44)

Lacroix R \& Dignat-George F 2012 Microparticles as a circulating source of procoagulant and fibrinolytic activities in the circulation. Thrombosis Research 129(Suppl 2) S27-S29. (doi:10.1016/j.thromres.2012.02.025)

Lacroix R, Judicone C, Poncelet P, Robert S, Arnaud L, Sampol J \& Dignat-George F 2012 Impact of pre-analytical parameters on the measurement of circulating microparticles: towards standardization of protocol. Journal of Thrombosis and Haemostasis $10437-446$. (doi:10.1111/j.1538-7836.2011.04610.x)

Lai RC, Arslan F, Lee MM, Sze NS, Choo A, Chen TS, Salto-Tellez M, Timmers L, Lee CN, El Oakley RM et al. 2010 Exosome secreted by MSC reduces myocardial ischemia/reperfusion injury. Stem Cell Research $\mathbf{4}$ 214-222. (doi:10.1016/j.scr.2009.12.003)

Lakhter AJ \& Sims EK 2015 Emerging Roles for Extracellular Vesicles in Diabetes and Related Metabolic Disorders. Molecular Endocrinology 29 1535-1548. (doi:10.1210/me.2015-1206)

Larson MC, Woodliff JE, Hillery CA, Kearl TJ \& Zhao M 2012 Phosphatidylethanolamine is externalized at the surface of microparticles. Biochimica et Biophysica Acta 1821 1501-1507. (doi:10.1016/j.bbalip.2012.08.017)

Lee C, Mitsialis SA, Aslam M, Vitali SH, Vergadi E, Konstantinou G, Sdrimas K, Fernandez-Gonzalez A \& Kourembanas S 2012 Exosomes mediate the cytoprotective action of mesenchymal stromal cells on hypoxia-induced pulmonary hypertension. Circulation 126 2601-2611. (doi:10.1161/CIRCULATIONAHA.112.114173)

Leroyer AS, Ebrahimian TG, Cochain C, Recalde A, Blanc-Brude O, Mees B, Vilar J, Tedgui A, Levy BI, Chimini G et al. 2009 Microparticles from ischemic muscle promotes postnatal vasculogenesis. Circulation 119 2808-2817. (doi:10.1161/CIRCULATIONAHA.108.816710)

Lindhardsen J, Kristensen SL \& Ahlehoff O 2015 Management of cardiovascular risk in patients with chronic inflammatory diseases: current evidence and future perspectives. American Journal of Cardiovascular Drugs [in press]. (doi:10.1007/s40256-015-0141-4)

Lobb RJ, Becker M, Wen SW, Wong CS, Wiegmans AP, Leimgruber A \& Moller A 2015 Optimized exosome isolation protocol for cell culture supernatant and human plasma. Journal of Extracellular Vesicles $\mathbf{4} 27031$. (doi:10.3402/jev.v4.27031)

Macey MG, Enniks N \& Bevan S 2011 Flow cytometric analysis of microparticle phenotype and their role in thrombin generation. Cytometry. Part B, Clinical Cytometry 80 57-63. (doi:10.1002/cyto. b.20551)

Mackie AR, Klyachko E, Thorne T, Schultz KM, Millay M, Ito A, Kamide CE, Liu T, Gupta R, Sahoo S et al. 2012 Sonic hedgehog-modified human $\mathrm{CD} 34+$ cells preserve cardiac function after acute myocardial infarction. Circulation Research 111 312-321. (doi:10.1161/ CIRCRESAHA.112.266015)

Martin S, Tesse A, Hugel B, Martinez MC, Morel O, Freyssinet JM \& Andriantsitohaina R 2004 Shed membrane particles from T lymphocytes impair endothelial function and regulate endothelial 
protein expression. Circulation 109 1653-1659. (doi:10.1161/01.CIR. $0000124065.31211 .6 \mathrm{E})$

Mathur S, Walley KR, Wang Y, Indrambarya T \& Boyd JH 2011 Extracellular heat shock protein 70 induces cardiomyocyte inflammation and contractile dysfunction via TLR2. Circulation Journal 75 2445-2452. (doi:10.1253/circj.CJ-11-0194)

Menasche P 2015 Stem cells in the management of advanced heart failure. Current Opinion in Cardiology 30 179-185. (doi:10.1097/HCO. 0000000000000138)

Mesri M \& Altieri DC 1998 Endothelial cell activation by leukocyte microparticles. Journal of Immunology $1614382-4387$.

Meziani F, Delabranche X, Asfar P \& Toti F 2010 Bench-to-bedside review: circulating microparticles-a new player in sepsis? Critical Care 14236. (doi:10.1186/cc9231)

Moldovan L, Batte K, Wang Y, Wisler J \& Piper M 2013 Analyzing the circulating microRNAs in exosomes/extracellular vesicles from serum or plasma by qRT-PCR. Methods in Molecular Biology 1024 129-145. (doi:10.1007/978-1-62703-453-1_10)

Nomura S, Komiyama Y, Murakami T, Funatsu A, Kokawa T, Sugo T, Matsuda M \& Yasunaga K 1993 Flow cytometric analysis of surface membrane proteins on activated platelets and platelet-derived microparticles from healthy and thrombasthenic individuals. International Journal of Hematology 58 203-212.

Ogata N, Nomura S, Shouzu A, Imaizumi M, Arichi M \& Matsumura M 2006 Elevation of monocyte-derived microparticles in patients with diabetic retinopathy. Diabetes Research and Clinical Practice 73 241-248. (doi:10.1016/j.diabres.2006.01.014)

Omoto S, Nomura S, Shouzu A, Hayakawa T, Shimizu H, Miyake Y, Yonemoto T, Nishikawa M, Fukuhara S \& Inada M 1999 Significance of platelet-derived microparticles and activated platelets in diabetic nephropathy. Nephron 81 271-277. (doi:10.1159/000045292)

Ong SG, Lee WH, Huang M, Dey D, Kodo K, Sanchez-Freire V, Gold JD \& Wu JC 2014 Cross Talk of Combined Gene and Cell Therapy in Ischemic Heart Disease: Role of Exosomal MicroRNA Transfer. Circulation 130 S60-S69. (doi:10.1161/CIRCULATIONAHA.113. 007917)

Perrone-Filardi P, Paolillo S, Costanzo P, Savarese G, Trimarco B \& Bonow RO 2015 The role of metabolic syndrome in heart failure. European Heart Journal 36 2630-2634. (doi:10.1093/eurheartj/ehv350)

Peters SA, Huxley RR \& Woodward M 2014 Diabetes as risk factor for incident coronary heart disease in women compared with men: a systematic review and meta-analysis of 64 cohorts including 858,507 individuals and 28,203 coronary events. Diabetologia 57 1542-1551. (doi:10.1007/s00125-014-3260-6)

Pironti G, Strachan RT, Abraham D, Mon-Wei YuS, Chen M, Chen W, Hanada K, Mao L, Watson LJ \& Rockman HA 2015 Circulating Exosomes Induced by Cardiac Pressure Overload Contain Functional Angiotensin II Type 1 Receptors. Circulation 131 2120-2130. (doi:10.1161/CIRCULATIONAHA.115.015687)

van der Pol E, Hoekstra AG, Sturk A, Otto C, van Leeuwen TG \& Nieuwland R 2010 Optical and non-optical methods for detection and characterization of microparticles and exosomes. Journal of Thrombosis and Haemostasis 8 2596-2607. (doi:10.1111/j.1538-7836. 2010.04074.x)

van der Pol E, Boing AN, Harrison P, Sturk A \& Nieuwland R 2012 Classification, functions, and clinical relevance of extracellular vesicles. Pharmacological Reviews 64 676-705. (doi:10.1124/pr.112.005983)

Pospichalova V, Svoboda J, Dave Z, Kotrbova A, Kaiser K, Klemova D, Ilkovics L, Hampl A, Crha I, Jandakova E et al. 2015 Simplified protocol for flow cytometry analysis of fluorescently labeled exosomes and microvesicles using dedicated flow cytometer. Journal of Extracellular Vesicles 4 article 25530. (doi:10.3402/jev.v4.25530)

Raposo G \& Stoorvogel W 2013 Extracellular vesicles: exosomes, microvesicles, and friends. Journal of Cell Biology 200 373-383. (doi:10.1083/jcb.201211138)
Rask-Madsen C \& King GL 2013 Vascular complications of diabetes: mechanisms of injury and protective factors. Cell Metabolism 17 20-33. (doi:10.1016/j.cmet.2012.11.012)

Raturi A, Miersch S, Hudson JW \& Mutus B 2008 Platelet microparticleassociated protein disulfide isomerase promotes platelet aggregation and inactivates insulin. Biochimica et Biophysica Acta 1778 2790-2796. (doi:10.1016/j.bbamem.2008.07.003)

Sahoo S, Klychko E, Thorne T, Misener S, Schultz KM, Millay M, Ito A, Liu T, Kamide C, Agrawal H et al. 2011 Exosomes from human CD34(+) stem cells mediate their proangiogenic paracrine activity. Circulation Research 109 724-728. (doi:10.1161/CIRCRESAHA.111.253286)

Scholz T, Temmler U, Krause S, Heptinstall S \& Losche W 2002 Transfer of tissue factor from platelets to monocytes: role of platelet-derived microvesicles and CD62P. Thrombosis and Haemostasis 88 1033-1038.

Sheldon H, Heikamp E, Turley H, Dragovic R, Thomas P, Oon CE, Leek R, Edelmann M, Kessler B, Sainson RC et al. 2010 New mechanism for Notch signaling to endothelium at a distance by Delta-like 4 incorporation into exosomes. Blood 116 2385-2394. (doi:10.1182/ blood-2009-08-239228)

Sinauridze EI, Kireev DA, Popenko NY, Pichugin AV, Panteleev MA, Krymskaya OV \& Ataullakhanov FI 2007 Platelet microparticle membranes have 50- to 100-fold higher specific procoagulant activity than activated platelets. Thrombosis and Haemostasis 97 425-434. (doi:10.1160/TH06-06-0313)

Skog J, Wurdinger T, van Rijn S, Meijer DH, Gainche L, Sena-Esteves M, Curry WT Jr, Carter BS, Krichevsky AM \& Breakefield XO 2008 Glioblastoma microvesicles transport RNA and proteins that promote tumour growth and provide diagnostic biomarkers. Nature Cell Biology 10 1470-1476. (doi:10.1038/ncb1800)

Sommeijer DW, Joop K, Leyte A, Reitsma PH \& ten Cate H 2005 Pravastatin reduces fibrinogen receptor gpIIIa on platelet-derived microparticles in patients with type 2 diabetes. Journal of Thrombosis and Haemostasis 3 1168-1171. (doi:10.1111/j.1538-7836.2005.01403.x)

Sreekumar PG, Kannan R, Kitamura M, Spee C, Barron E, Ryan SJ \& Hinton DR $2010 \alpha \mathrm{B}$ crystallin is apically secreted within exosomes by polarized human retinal pigment epithelium and provides neuroprotection to adjacent cells. PLOS ONE 5 e12578. (doi:10.1371/journal. pone.0012578)

Stepanian A, Bourguignat L, Hennou S, Coupaye M, Hajage D, Salomon L, Alessi MC, Msika S \& de Prost D 2013 Microparticle increase in severe obesity: not related to metabolic syndrome and unchanged after massive weight loss. Obesity 21 2236-2243. (doi:10.1002/oby.20365)

Suades R, Padro T \& Badimon L 2015 The Role of Blood-Borne Microparticles in Inflammation and Hemostasis. Seminars in Thrombosis and Hemostasis 41 590-606. (doi:10.1055/s-0035-1556591)

Teede H, Deeks A \& Moran L 2010 Polycystic ovary syndrome: a complex condition with psychological, reproductive and metabolic manifestations that impacts on health across the lifespan. BMC Medicine 8 41. (doi:10.1186/1741-7015-8-41)

Thery C, Amigorena S, Raposo G \& Clayton A 2006 Isolation and characterization of exosomes from cell culture supernatants and biological fluids. Current Protocols in Cell Biology Chapter 3, Unit 3.22. (doi:10.1002/0471143030.cb0322s30)

Thery C, Ostrowski M \& Segura E 2009 Membrane vesicles as conveyors of immune responses. Nature Reviews. Immunology 9 581-593. (doi:10.1038/nri2567)

Trajkovic K, Hsu C, Chiantia S, Rajendran L, Wenzel D, Wieland F, Schwille P, Brugger B \& Simons M 2008 Ceramide triggers budding of exosome vesicles into multivesicular endosomes. Science $\mathbf{3 1 9}$ 1244-1247. (doi:10.1126/science.1153124)

Tsimerman G, Roguin A, Bachar A, Melamed E, Brenner B \& Aharon A 2011 Involvement of microparticles in diabetic vascular complications. Thrombosis and Haemostasis 106 310-321. (doi:10.1160/TH10-11-0712)

Tushuizen ME, Diamant M, Peypers EG, Hoek FJ, Heine RJ, Sturk A \& Nieuwland R 2012 Postprandial changes in the phospholipid composition of circulating microparticles are not associated with coagulation

Published by Bioscientifica Ltd. 
activation. Thrombosis Research 130 115-121. (doi:10.1016/j.thromres. 2011.09.003)

Ueba T, Haze T, Sugiyama M, Higuchi M, Asayama H, Karitani Y, Nishikawa T, Yamashita K, Nagami S, Nakayama T et al. 2008 Level, distribution and correlates of platelet-derived microparticles in healthy individuals with special reference to the metabolic syndrome. Thrombosis and Haemostasis 100 280-285. (doi:10.1160/TH07-11-0668)

Valadi H, Ekstrom K, Bossios A, Sjostrand M, Lee JJ \& Lotvall JO 2007 Exosome-mediated transfer of mRNAs and microRNAs is a novel mechanism of genetic exchange between cells. Nature Cell Biology 9 654-659. (doi:10.1038/ncb1596)

Vicencio JM, Yellon DM, Sivaraman V, Das D, Boi-Doku C, Arjun S, Zheng Y, Riquelme JA, Kearney J, Sharma V et al. 2015 Plasma exosomes protect the myocardium from ischemia-reperfusion injury. Journal of the American College of Cardiology 65 1525-1536. (doi:10.1016/j.jacc.2015. 02.026)

Villarroya-Beltri C, Gutierrez-Vazquez C, Sanchez-Cabo F, Perez-Hernandez D, Vazquez J, Martin-Cofreces N, Martinez-Herrera DJ, Pascual-Montano A, Mittelbrunn M \& Sanchez-Madrid F 2013 Sumoylated hnRNPA2B1 controls the sorting of miRNAs into exosomes through binding to specific motifs. Nature Communications 42980. (doi:10.1038/ncomms3980)

Vrijsen KR, Sluijter JP, Schuchardt MW, van Balkom BW, Noort WA, Chamuleau SA \& Doevendans PA 2010 Cardiomyocyte progenitor cell-derived exosomes stimulate migration of endothelial cells. Journal of Cellular and Molecular Medicine 14 1064-1070. (doi:10.1111/ j.1582-4934.2010.01081.x)

Wang JG, Williams JC, Davis BK, Jacobson K, Doerschuk CM, Ting JP \& Mackman N 2011 Monocytic microparticles activate endothelial cells in an IL-1 $\beta$-dependent manner. Blood 118 2366-2374. (doi:10.1182/ blood-2011-01-330878)

Wang Y, Chen LM \& Liu ML 2014a Microvesicles and diabetic complications-novel mediators, potential biomarkers and therapeutic targets. Acta Pharmacologica Sinica 35 433-443. (doi:10.1038/aps. 2013.188)

Wang X, Huang W, Liu G, Cai W, Millard RW, Wang Y, Chang J, Peng T \& Fan GC 2014b Cardiomyocytes mediate anti-angiogenesis in type 2 diabetic rats through the exosomal transfer of miR-320 into endothelial cells. Journal of Molecular and Cellular Cardiology 74 139-150. (doi:10.1016/j.yjmcc.2014.05.001)
Welton JL, Webber JP, Botos LA, Jones M \& Clayton A 2015 Ready-made chromatography columns for extracellular vesicle isolation from plasma. Journal of Extracellular Vesicles 4 27269. (doi:10.3402/jev.v4. 27269)

Werner N, Wassmann S, Ahlers P, Kosiol S \& Nickenig G 2006 Circulating CD31+/annexin $\mathrm{V}+$ apoptotic microparticles correlate with coronary endothelial function in patients with coronary artery disease. Arteriosclerosis, Thrombosis, and Vascular Biology 26 112-116. (doi:10.1161/01.ATV.0000191634.13057.15)

Willis GR, Connolly K, Ladell K, Davies TS, Guschina IA, Ramji D, Miners K, Price DA, Clayton A, James PE et al. 2014 Young women with polycystic ovary syndrome have raised levels of circulating annexin V-positive platelet microparticles. Human Reproduction 29 2756-2763. (doi:10.1093/humrep/deu281)

Witwer KW, Buzas EI, Bemis LT, Bora A, Lasser C, Lotvall J, Nolte 't-Hoen EN, Piper MG, Sivaraman S, Skog J et al. 2013 Standardization of sample collection, isolation and analysis methods in extracellular vesicle research. Journal of Extracellular Vesicles 2 article 20360. (doi:10.3402/ jev.v2i0.20360)

Wolf P 1967 The nature and significance of platelet products in human plasma. British Journal of Haematology 13 269-288. (doi:10.1111/ j.1365-2141.1967.tb08741.x)

Yellon DM \& Davidson SM 2014 Exosomes: nanoparticles involved in cardioprotection? Circulation Research 114 325-332. (doi:10.1161/ CIRCRESAHA.113.300636)

Yoon YS, Wecker A, Heyd L, Park JS, Tkebuchava T, Kusano K, Hanley A, Scadova H, Qin G, Cha DH et al. 2005 Clonally expanded novel multipotent stem cells from human bone marrow regenerate myocardium after myocardial infarction. Journal of Clinical Investigation 115 326-338. (doi:10.1172/JCI200522326)

Yu B, Kim HW, Gong M, Wang J, Millard RW, Wang Y, Ashraf M \& Xu M 2015 Exosomes secreted from GATA-4 overexpressing mesenchymal stem cells serve as a reservoir of anti-apoptotic microRNAs for cardioprotection. International Journal of Cardiology 182C 349-360. (doi:10.1016/j.ijcard.2014.12.043)

Zhang Y, Zhang X, Shan P, Hunt CR, Pandita TK \& Lee PJ 2013 A protective Hsp70-TLR4 pathway in lethal oxidant lung injury. Journal of Immunology 191 1393-1403. (doi:10.4049/jimmunol.1300052)

Zhang B, Yin Y, Lai RC, Tan SS, Choo AB \& Lim SK 2014 Mesenchymal stem cells secrete immunologically active exosomes. Stem Cells and Development 23 1233-1244. (doi:10.1089/scd.2013.0479)

Received in final form 2 October 2015

Accepted 19 November 2015 http://joe.endocrinology-journals.org

DOI: 10.1530/JOE-15-0201
(C) 2016 Society for Endocrinology Printed in Great Britain 